\title{
Capsule Commentary on Trowbridge et al., Development and Impact of a Novel Academic Primary Compensation Model
}

\author{
Sami Tahhan, MD, FACP \\ Department of Internal Medicine, Eastern Virginia Medical School (EVMS), Norfolk, VA, USA.
}

J Gen Intern Med 30(12): 1856

DOI: $10.1007 / \mathrm{s} 11606-015-3457-5$

(c) Society of General Internal Medicine 2015

$\mathrm{T}$ he observational study by Trowbridge et al. relates to a novel academic primary care physician compensation model. ${ }^{1}$ The institution faced a crisis in retaining academic general internists using a compensation model based on RVUs (relative value units). It responded by stabilizing salaries for a year and engaging consultants to prioritize needs and empower the stakeholders. Focus groups were created to identify the most important aspects of compensation. Using this information, the leadership came up with three compensation models which were voted upon by the faculty, with an overwhelming majority choosing a compensation plan which had a $50 \%$ salary base, with an additional $25 \%$ coming from panel size and an additional $25 \%$ coming from patient visit productivity. $^{2}$

In addition to improving retention, internal medicine academic physicians had greater satisfaction with the payment plan structure and annual salary. Panel sizes increased, lining up with the need for population health priorities, though there was a drop in overall RVUs. ${ }^{3,4}$

Interpretation of the findings is hampered by the fact that the comparison group comprised family practitioners and pediatricians at their institution rather than academic internists at other institutions, and by the lack of an examination of their data before and after changes were instituted.

Nevertheless, this study addresses a timely issue in general internal medicine at academic centers: How do you reconcile quality of care without affecting volume, productivity, salaries and physician compensation and satisfaction, while improving patient care? The physician model discussed by the authors appears to be successful at their institution, but came at a financial cost to the institution, making it less likely that it can be widely applied.

For clinicians and administrators, this study provides a good example of how to respond to an unfavorable situation. It demonstrates the importance of obtaining buy-in at all levels by involving outside help through consultants and internal creative physician panel discussions in order to come up with innovative solutions. ${ }^{5}$ It also demonstrates the benefit of a democratic process through voting on the best plan of action. All in all, an excellent lesson in teamwork.

Conflict of Interest: The author has no conflicts of interest with this article.

Corresponding Author: Sami Tahhan, MD, FACP; Department of Internal Medicine Eastern Virginia Medical School (EVMS), Norfolk, VA 23507, USA (e-mail: tahhansg@evms.edu).

\section{REFERENCES}

1. Trowbridge E, Bartels CM, Koslov S, Kamnetz S, Pandhi N. Development and impact of a novel academic primary care compensation model. J Gen Intern Med. 2015. doi:10.1007/s11606-015-3410-7.

2. Chen MA, Hollenberg JP, Michelen W, Peterson JC, Casalino LP. Patient care outside of office visits: a primary care physician time study. J Gen Intern Med. 2011;26:58-63.

3. Solomon J. How strategies for managing patient visit time affect physician job satisfaction: a qualitative analysis. J Gen Intern Med. 2008;23:775-80.

4. Schroeder SA, Frist W. Phasing out fee-for-service payment. N Engl J Med. 2013;368:2029-32.

5. Kotter JP. Leading change: why transformation efforts fail. Har Bus Rev. 1995:59-67.

This comment refers to the article available at: http://dx.doi.org/10.1007/ s11606-015-3410-7.

Published online July 10, 2015 